\title{
Dominique Avon (éd.), La Caricature au risque des autorités politiques et religieuses
}

Rennes, Presses universitaires de Rennes, 2010, 202 p. ill.

Isabelle Saint-Martin

\section{(2) OpenEdition}

\section{Journals}

Édition électronique

URL : http://journals.openedition.org/assr/23441

DOI : $10.4000 /$ assr. 23441

ISSN : $1777-5825$

Éditeur

Éditions de l'EHESS

Édition imprimée

Date de publication : 31 décembre 2011

Pagination : 98

ISBN : 9782713223273

ISSN : 0335-5985

Référence électronique

Isabelle Saint-Martin, « Dominique Avon (éd.), La Caricature au risque des autorités politiques et religieuses », Archives de sciences sociales des religions [En ligne], 156 | octobre-décembre 2011, document 156-9, mis en ligne le 14 février 2012, consulté le 21 septembre 2020. URL : http:// journals.openedition.org/assr/23441; DOI : https://doi.org/10.4000/assr.23441

Ce document a été généré automatiquement le 21 septembre 2020.

(c) Archives de sciences sociales des religions 


\title{
Dominique Avon (éd.), La Caricature au risque des autorités politiques et religieuses
}

Rennes, Presses universitaires de Rennes, 2010, 202 p. ill.

\author{
Isabelle Saint-Martin
}

\section{RÉFÉRENCE}

Dominique AVON (éd.), La Caricature au risque des autorités politiques et religieuses, Rennes, Presses universitaires de Rennes, 2010, 202 p. ill.

Dirigé par un spécialiste des relations entre christianisme et islam, Dominique Avon, professeur d'histoire contemporaine à l'université du Maine, cet ouvrage collectif s'ouvre, dès l'introduction, par une mise en perspective de l'«affaire des caricatures de Mahomet». Il s'agit, à travers l'exemple de cette crise majeure, de mettre en évidence «les usages de conceptions du sacré dans l'espace public à l'époque contemporaine». Alors que l'affaire a suscité d'innombrables réactions dans la presse ainsi que quelques ouvrages tentant une lecture plus globale (rappelons ceux, d'esprit fort différent, de Mohammed Sifaoui, L'affaire des caricatures: dessins et manipulations, 2006, ou de Jeanne Favret-Saada, Comment produire une crise mondiale avec douze petits dessins, 2007), il y avait place pour une analyse du déroulé de la crise et des prises de position médiatiques si multiples qui l'ont entourée. L'un des très grands mérites de ce collectif est de s'y atteler avec des approches diverses, toutefois le projet initial était, semble-t-il, plus vaste et voulait offrir un aperçu général des attitudes autour du support que constitue la «caricature du sacré religieux ou politique», les deux étant souvent intimement liés. L'auteur déplore des défections de dernière minute notamment sur le cas israélien ou le cas turc et l'on comprend qu'il n'ait pas été possible de retarder davantage la sortie d'un ouvrage lié à un débat qui a marqué l'actualité des dernières années. Il reste une dizaine de contributions réunies en deux parties distinctes: «Traditions de la caricature 
politique et religieuse» et "L'affaire des caricatures de Mahomet sous différents climats». Dans la première figurent cinq interventions, deux sur la France, une sur la Russie, une sur le Liban et l'Iran, une enfin sur les relations islamo-chrétiennes au miroir de la caricature religieuse en Indonésie. Cette étude de Rémy Madinier comporte également un riche développement sur les retentissements des caricatures danoises mettant en évidence, outre le sentiment d'agression face à un Occident sûr de ses valeurs, la façon dont cette sorte d'exorcisme occidental de la peur du terrorisme a pu pointer les contradictions présentes en Indonésie alors que la violence religieuse y était forte. Elle aurait assez facilement pu s'intégrer à la seconde partie et, comme deux des articles de cette première partie portent sur l'islam, il faut reconnaitre, en dépit de la qualité et de l'intérêt de ces textes, que les choix semblent un peu arbitraires et que la cohérence de l'ensemble n'est pas parfaite. Deux interventions couvrent un champ chronologique très large. Le parcours de Christian Amalvi sur les reproductions d'œuvres d'art religieux, puis leur usage parodique, va du Second Empire à nos jours et ne se limite pas à la question des caricatures. L'auteur y reprend certaines de ses précieuses analyses sur l'illustration des manuels scolaires au xIX siècle et étend le regard jusqu'aux détournements des surréalistes ou de la presse contemporaine. La synthèse de Lorraine de Meaux sur la Russie court également de la fin du XIX ${ }^{e}$ siècle jusqu'à la perestroïka afin de situer les grandes lignes d'évolution d'un genre qui trouve difficilement sa place sous une succession de régimes autoritaires et doit jouer, là plus qu'ailleurs, de l'implicite et des sous-entendus. Philippe Rocher traite au contraire d'une étude de cas très précise. Il apporte sur la caricature de l'éducation jésuite en France (1814-1914) un intéressant complément à l'ouvrage sur Les Antijésuites, Discours, lieux et figures de l'antijésuitisme, à l'époque moderne (dir. P.A. Fabre et C. Maire), publié la même année chezle même éditeur et dont l'auteur n'a sans doute pu avoir connaissance alors. À travers l'exemple des portraits de religieux au Liban et en Iran, qui témoignent de la place de l'image dans le monde chiite, Anaïs-Trissa Khatchadourian et Sabine Salhab dressent une analyse tout à la fois politique et religieuse tant ces dimensions sont liées dans ces photographies et caricatures de leaders gouvernementaux.

2 La seconde partie de l'ouvrage est au contraire entièrement consacrée à l'affaire danoise et à ses répercussions. Il n'est pas inutile de commencer par lire la chronologie de la crise que Dominique Avon a placée en annexe et qui offre, au-delà d'un simple rappel des faits, une véritable mise en perspective du dossier. On peut ensuite reprendre avec le même auteur l'étude détaillée des réactions dans la presse française. Trois axes en émergent. Le conflit entre liberté d'expression et respect des croyances est bien sûr central; il fait surgir le soupçon d'une collision des religions pour «sanctuariser leurs symboles». La question de la représentation du prophète en Islam a également occupé le débat médiatique mettant ainsi en lumière les fluctuations, selon les époques et les traditions sunnites ou chiites, des critères invoqués et des marges de manœuvre. Enfin, les discriminations et violences tant au Danemark que dans les pays musulmans ont suscité de multiples commentaires. La réalité de la caricature dans le monde arabe et son antisémitisme plus que latent ont été soulignés à la suite des travaux de Joël Kotek. L'examen plus serré des ressorts de la crise a mis en évidence le rôle déclencheur de quelques imams controversés au Danemark ainsi que la crainte des autorités du monde arabe de se voir dépassées sur ce sujet par les groupes fondamentalistes. 
3 L'enquête est poursuivie par trois autres contributions. Celle d'Augustin Jomier choisit de s'en tenir à la réception de l'affaire en Algérie afin d'en envisager les ressorts locaux dans un pays qui possède une presse indépendante et une relative liberté d'expression. Richard Tholoniat prend pour objet quatre grands quotidiens de la presse britannique dite «de qualité» et interroge, outre la question de la liberté d'expression, celle des relations multiethniques au Royaume-Uni, pays où les caricatures n'ont pas été reproduites. Pierre Guerlain reprend l'affaire sous l'angle des débats américains sur la liberté d'expression. Débats auxquels se sont greffées très tôt les oppositions entre la droite et la gauche sur le sujet de la xénophobie - avec des situations parfois à fronts renversés - ainsi que les effets du conflit israélo-palestinien, tant la lecture de cette crise ne peut se faire indépendamment de la politique internationale. En dernier lieu, peut-être peut-on regretter que l'initiative judicieuse de rassembler en fin d'ouvrage une page d'orientation bibliographique ait repris plusieurs titres dont l'intérêt ne se justifiait qu'au regard de certains des articles rassemblés et négligé des synthèses et des études plus directement liées au domaine de la caricature, notamment les travaux d'historiens de l'art tels que F. Boespflug, L. Baridon et M. Guedron, S. Le Men, entre autres, alors que ce support graphique appelle tout particulièrement à croiser les regards au-delà des frontières disciplinaires. Mais les contributions réunies sur ce thème sensible contribuent de manière précieuse à éclairer la réception de cette crise dans des pays de contexte confessionnel et politique variés, en montrant une grande complexité des liens entre liberté d'expression et degré de l'avancement démocratique selon les États ou les discours étudiés. 